\title{
Effects of probiotics and synbiotic on lipid profiles in adults at risk of type 2 diabetes: A double-blind randomized controlled clinical trial
}

\author{
Nazila Kassaian', Awat Feizi ${ }^{2}$, Ashraf Aminorroaya ${ }^{3}$, Maryam Tajabadi Ebrahimi ${ }^{4}$, Atsa \\ Norouzi $^{5}$, Masoud Amini ${ }^{3}$
}

${ }^{1}$ Infectious Diseases and Tropical Medicine Research Center, Isfahan University of Medical Sciences, Isfahan, Iran; ${ }^{2}$ Isfahan Endocrine and Metabolism Research Center and Department of Biostatistics and Epidemiology, Isfahan University of Medical Sciences, Isfahan, Iran; ${ }^{3}$ Isfahan Endocrine and Metabolism Research Center, Isfahan University of Medical Sciences, Isfahan, Iran; ${ }^{4}$ Microbiology Department, Science faculty, Islamic Azad University (IAU), Tehran Central branch, Tehran, Iran; ${ }^{5}$ Isfahan Endocrine and Metabolism Research Center, Isfahan University of Medical Sciences, Isfahan, Iran

Corresponding author: Prof. Masoud Amini, Isfahan Endocrine and Metabolism Research Center, Sedighe Tahere Research Complex, Khoram St., Isfahan, Iran.

Submission Date: May 20, 2019. Acceptance Date: July $28^{\text {th }}$, 2019. Publication Date: July $31^{\text {st }}$, 2019

Citation: Kassaian N., Feizi A., Aminorroaya A., Ebrahimi M., Norouzi A., Amini M. Effects of probiotics and synbiotic on lipid profiles in adults at risk of type 2 diabetes: A double-blind randomized controlled clinical trial. Functional Foods in Health and Disease 2019; 9(7): 494-507. DOI: https://doi.org/10.31989/ffhd.v9i7.617

\section{ABSTRACT}

Background: The use of probiotics and/or prebiotics as an effective means of regulating gut microbiota may have a beneficial effect on metabolic disorders.

Aims: This study was designed to assess the ability of probiotics and synbiotic to modify lipid profiles in subjects with prediabetes who are at risk of diabetes and cardiovascular diseases.

Methods: In a randomized double-blind placebo-controlled clinical trial, 120 pre-diabetic adults aged 35-70 years from the first-degree family of type 2 diabetic patients were recruited and randomly equally assigned to consume $6 \mathrm{~g} / \mathrm{d}$ either probiotic or synbiotic or placebo supplements for 6 months. The probiotics used were Lactobacillus acidophilus, Bifidobacterium bifidum, Bifidobacterium lactis, and Bifidobacterium longum. Food record, physical activity, anthropometric measures and lipid profiles were assessed repeatedly at baseline, and 3- and 6month supplementation. 
Results: Probiotics and synbiotic were effective in reduction of serum triglycerides after 6 months of intervention (SMD=- 10.6 and -9.4 respectively). Compared with the placebo, synbiotic resulted in a significant reduction in serum triglyceride levels $(\mathrm{MD} \pm \mathrm{SE}:-9.4 \pm 6.6 \mathrm{mg} / \mathrm{dl} \mathrm{vs} .+13.2 \pm 6.8$ $\mathrm{mg} / \mathrm{dl}, \mathrm{p}=0.02$ ). Serum total-, LDL-, and HDL-cholesterol were statistically unaffected by probiotic or synbiotic.

Conclusion: The results of this study showed that supplementation with probiotic and especially synbiotic could decrease the concentration of triglyceride in prediabetic adults. This finding could warrant future studies to determine the therapeutic and preventive effects of these supplements in individuals at risk of diabetes and cardiovascular diseases.

Trial registration: Iranian Registry of Clinical Trials: IRCT201511032321N2. Date registered: February 27, 2016.

Keywords: probiotic; synbiotic; prediabetes; lipid; lipoprotein

\section{INTRODUCTION}

Diabetes mellitus and prediabetes are becoming serious public health problems in the world. Moreover, cardiovascular disease (CVD) is the most leading cause of death and the major complication of type 2 diabetes mellitus (T2DM) and prediabetes (1). It has been demonstrated that impaired insulin metabolism predisposes individuals at risk of type 2 diabetes to CVD through dyslipidemia. So, the alteration in plasma lipid and lipoprotein profile has been strongly documented in diabetic and pre-diabetic patients (2). The central goal in CVD prevention and treatment is reducing the levels of serum cholesterol, low-density lipoprotein (LDL) cholesterol, and triglycerides as well as increasing in high-density lipoprotein (HDL) cholesterol (3). The pathogenesis of type 2 diabetes and cardiovascular diseases involves both genetic and environmental factors $(4,5)$, among which gut microbiota as a new approach, play an important role $(6,7)$. The association between gut microbiota and diseases has been set forth the demand for new functional products (8). It is suggested that consumption of probiotics and/or prebiotics as the functional foods would be a good approach for this meaning (9). Probiotics are live microorganisms that when administered in adequate amounts could confer a health benefit on the host (10,11). The most two commonly used groups of probiotic bacteria, are Lactobacillus and Bifidobacterium (12). Some studies indicated that probiotics may be able to decrease the levels of total cholesterol (TC), LDL-c and balance the ratio of LDL-c/HDL-c (13).

Prebiotics are non-digestible oligosaccharides that their use as the food ingredients on health has been recently triggered much research. Among other beneficial effects of prebiotics, the blood lipid reduction is of particular interest (14). Synbiotic that contains both probiotics and prebiotics is used to effectively modulate gut microbiota and the health benefit can be synergistic. The beneficial effects of synbiotic could be via mechanisms such as gut hormone balance, energy 
storage and dietary energy expenditure, production of short chain fatty acids (SCFA), and improvement in immune function and insulin resistance (15).

Therefore, it is hypothesized that supplementation with probiotic or prebiotic or synbiotic might be effective on the lipid and lipoprotein profile improvement. Understanding the role of probiotics or synbiotics on lipid profiles may provide ideas for new prevention and treatment strategies in cardiovascular disease and the other complications of diabetes and prediabetes.

However, there is the contradiction about this conception in previous studies (16). In view of the limited number of high-quality clinical trials in this regard and the contradictory results, the present study was designed to investigate and compare the effects of probiotics and synbiotic supplementation on lipid and lipoprotein profiles in pre-diabetic patients in a double blind randomized controlled parallel groups clinical trial.

\section{MATERIALS AND METHODS}

\section{Participants}

The participants with prediabetes were selected from the first-degree relatives of type 2 diabetic patients in Isfahan Endocrine and Metabolism Research Center outpatient clinic, Iran.

Diagnosis of prediabetes was based on the criteria of American Diabetes Association (17); those with one of the following criteria: fasting plasma glucose (FPG) 100-125 mg/dl and/or blood sugar (BS) 2-h pp 140-199 mg/dl via oral glucose tolerance test (OGTT). Individuals (men and women) aged 35 to 70 years old with the above-mentioned inclusion criteria were called to participate in the study.

The exclusion criteria were suspected or definite history of alcohol or drug abuse, currently smoking, using probiotic, prebiotic or synbiotic during the past 3 months, antibiotic or laxatives use in the past 3 months or during the study, pregnancy, having food allergies, celiac or irritable bowel disease, having severe liver, kidney, heart or nervous system diseases, currently taking nonsteroidal anti-inflammatory drugs, antipsychotics, or nicotinic acid. If a participant missed more than 10 percent of supplement dose (defined to non-compliance) or had irritable or any kind of allergy to studied agents, he or she excluded from the study at any stage of the investigation. Also, the participants were excluded from the study if there was any change in medication, modify in lifestyle or start antibiotics at any stage of the investigation.

\section{Study Design}

The study was a randomized, double-blind, placebo- controlled, three-arms, and parallel-group clinical trial on prediabetic subjects which was designed according to the CONSORT 2010 and SPIRIT 2013 guidelines (18). The participants were randomly assigned into three equal groups to receive either probiotic or synbiotic or placebo for 6 months using block stratified randomization method (stratified for gender and age). The randomization list was provided by a person who not involved in the study using numbered containers to implement the random allocation sequence. Investigators, participants, and laboratory staff were blinded to the allocation of the three 
supplements. The appearance and packaging of the three products were identical. The blinding code was provided to the investigators after completing the statistical analyses.

The participants advised not to modify daily dietary and physical activity habits during the study period. To ensure that these habits had not been modified during the study, the participants were instructed to record 3 days' food and physical activity diaries and checked by a dietitian at the baseline and follow-ups.

Also, the participants were advised not to modify their medication during the experiment. Adherence to treatment was assessed by weekly phone calls, during regularly scheduled appointments, and by returned sachet counts.

Time schedule of enrolment, interventions, assessments, and visits for participants has been shown in table 1.

Table 1. Time schedule of enrolment, interventions, assessments, and visits for participants

\begin{tabular}{|c|c|}
\hline Time & Visits and Activities \\
\hline Prior to starting the study & $\begin{array}{l}\text { The patients who have eligibility criteria were asked to read } \\
\text { and sign the consent form. The patients were instructed on } \\
\text { writing the food and physical activity records. They were } \\
\text { asked not to give any other dietary supplementation and not } \\
\text { to change their medication and/or life style during the study } \\
\text { and to inform the investigators if they had been prescribed } \\
\text { oral antibiotics at any time during the study. }\end{array}$ \\
\hline Start of study & $\begin{array}{l}\text { Food and physical activity records were collected. Weight } \\
\text { and height were measured. Lipid profile tests were } \\
\text { performed. The supplements were delivered. }\end{array}$ \\
\hline Week $2,4,9$ & $\begin{array}{l}\text { Contacted with the participants and effectiveness or adverse } \\
\text { events were recorded. }\end{array}$ \\
\hline Week 12 & $\begin{array}{l}\text { Food and physical activity records were collected. Weight } \\
\text { and height were measured. Lipid profile tests were } \\
\text { performed. The supplements were delivered. }\end{array}$ \\
\hline Week 14, 16, 18, 20 & $\begin{array}{l}\text { Contacted with the participants and effectiveness or adverse } \\
\text { events were recorded. }\end{array}$ \\
\hline Week 24 & $\begin{array}{l}\text { Food and physical activity records were collected. Weight } \\
\text { and height were measured. Lipid profile tests were } \\
\text { performed. }\end{array}$ \\
\hline
\end{tabular}




\section{Ethics statements}

The study protocol was conducted according to the principles expressed in the Declaration of Helsinki and has been approved by the Ethics Committee of Isfahan University of Medical Sciences (approval number: IR.MUI.REC.1394.3.813). The trial has been registered at Iranian Registry of Clinical Trials as IRCT201511032321N2.The purpose of the study, benefits or side effects of the supplements were fully explained to all participants and written informed consent was obtained prior to the commencement of study. The personal information of enrolled participants was collected via encoding procedures.

\section{Intervention}

The participants were instructed to consistently take 6 grams of the supplements diluted in a cup of water and drink it each day after main meal (lunch or dinner) to minimize the killing of the probiotic by gastric acid for 6 months.

The probiotic sachet contained the freeze-dried Lactobacillus acidophilus, Bifidobacterium bifidum, Bifidobacterium lactis, and Bifidobacterium longum $\left(1.5 \times 10^{9} \mathrm{CFU}\right.$ for each) with maltodextrin as the filler. Synbiotic comprised the above-mentioned probiotics plus inulin as prebiotic and placebo included maltodextrin. The synbiotic was designed in the present study for the first time in Iran. All of the microbial and purity tests had been checked by two independent microbiologists and the solubility and palatability of supplements had been assessed to determine the optimal well-tolerated mode of delivery of the supplement prescription. The supplements were prepared and packaged in Tak Gen Zist Pharmaceutical Company, Tehran, Iran.

\section{Biochemical assessments}

Fasting blood samples $(10 \mathrm{~mL})$ were taken at baseline and after 3 and 6 months of intervention at the Isfahan Endocrine and Metabolism Research Center laboratory in the early morning after 12 hours overnight fast. The participants were instructed not to do vigorous physical activity for the previous 48 hours. Plasma lipids and lipoproteins concentrations (i.e., triglycerides, total cholesterol, and high- and low-density lipoprotein cholesterol) were measured using a photometric assay kit (Pars Azmoon Co., Tehran, Iran).

\section{Anthropometric measurements}

Height and weight were measured at baseline and repeated at months 3 and 6 .

Height was determined using a scale-mounted stadiometer to the nearest $0.5 \mathrm{~cm}$ and weight was measured with light clothing to the nearest $0.1 \mathrm{~kg}$. BMI was calculated by dividing weight in kilograms by squared height in meters. All of the measurements were taken by a trained nutritionist 
to decrease the error rate. Furthermore, the nutritionist was blinded to the randomization assignments.

\section{Food Intake and Physical Activity Assessments}

Participants were instructed to record their daily food and beverage intake for 3 days (2 weekdays and one weekend) at baseline, 3 months and 6 months of the intervention period. The records were analyzed for energy content and macro nutrients (carbohydrate, protein and fat) using Nutritionist IV software (First Databank, San Bruno, CA). Physical activity records were assessed using the metabolic equivalent of task (MET) questionnaire. To measure the METs for each participant, the times (in hour per day) reported for each physical activity was multiplied by its related METs coefficient via standard tables (19).

\section{Statistical Analysis}

Sample size calculation was based on a parallel three-group randomized clinical trial with repeated measurements of main outcomes at three-time points. Considering type one error rate of $\alpha=0.05$ and statistical power $80 \%$ for detecting at least a standardized effect size of $\Delta=0.75$ (20), 29 subjects were determined in each group. For compensating the possible attrition, 30\% additional samples were recruited, in which finally 40 subjects in each study group were participated.

Recorded data were double-entered on SPSS software Version 15 (SPSS Inc., Chicago, IL, USA). Categorical and continuous data were presented as frequency (percentage) and mean \pm standard deviation (SD) respectively. After assessment of the normal distribution by Kolmogorov-Smirnov test, inter and intra-group changes were compared by a repeated measure analysis of variance. Analysis of variance (ANOVA) was used to compare the difference between three groups at each time point. Bonferroni correction was applied to account for multiple testing in the comparisons to infer which means differed. In the framework of repeated measures ANOVA, sphericity assumption was evaluated using Muchly test, and multivariate approach or Huynh-Feldt was considered when appropriate. A post-power analysis for determining the statistical power of the differences which observed between groups was conducted. Baseline values of measured outcomes were adjusted as covariates when they were significantly different between groups. The presented $\mathrm{p}$-values are based on adjusting for the multiple testing and the value of $P<0.05$ was considered statistically significant. Statistical analyses were conducted in the framework of per protocol.

\section{RESULTS}

A total of 224 prediabetic individuals (152 females and 72 males) were called to enter the study. Among them 104 subjects were excluded because they declined to participate or did not fulfilling 
the inclusion criteria. From 120 individuals who were participated and randomly assigned into the three study groups, 30 participants were dropped out before the first 3 months and 5 ones between 3 and 6 months of the intervention period because of using antibiotic during the study, low compliance, disinclination, GI complications, and traveling. Finally, the data for 85 participants who had completed the 6-months' intervention (27 in probiotic, 30 in synbiotic and 28 in placebo groups) were analyzed. Screening, enrollment, and retention of the participants are shown in Figure 1. There were no statistically significant differences between the groups whom completed interventions and the lost to follow-up/discontinued in baseline lipid profiles and anthropometric measures (Table 2). The included participants (the participants who completed study period) were 38 males $(45 \%)$ and 47 females $(55 \%)$ with the mean age $52.95 \pm 6.3$ years.

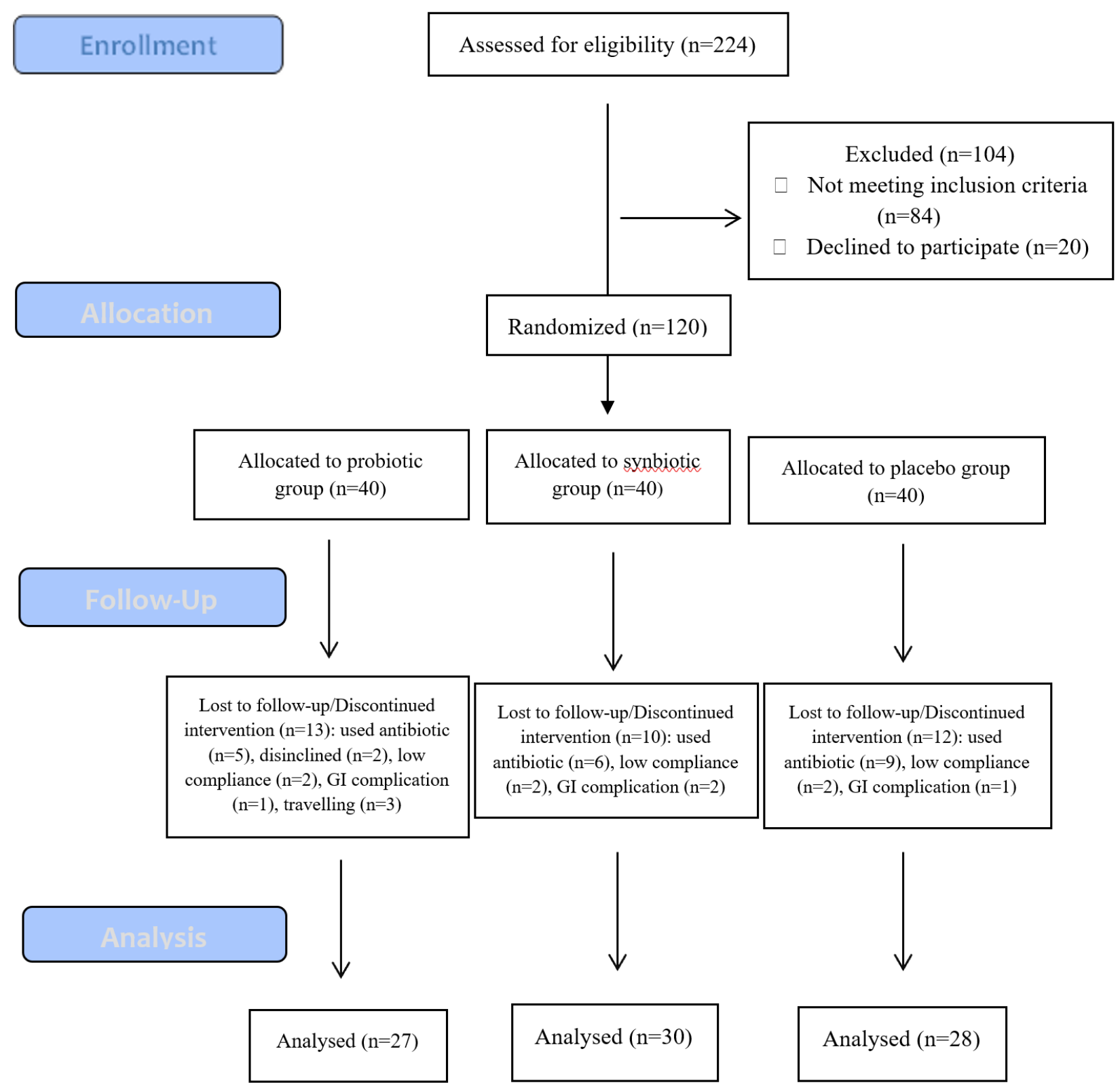

Figure 1. Prediabetic Participants’ Flow (Diagram CONSORT 2010) 
Table 2. The status of lipid profiles in those who completed interventions and lost to followup/discontinued participants.

\begin{tabular}{|l|l|l|l|}
\hline & $\begin{array}{l}\text { Completed Intervention } \\
\text { Group } \\
\text { mean } \pm \text { SD } \\
\mathbf{n}=\mathbf{8 5}\end{array}$ & $\begin{array}{l}\text { Lost to Follow- } \\
\text { up/Discontinued } \\
\text { Intervention Group } \\
\text { mean } \pm \text { SD } \\
\mathbf{n}=35\end{array}$ & P-value* \\
\hline $\begin{array}{l}\text { Triglyceride } \\
\text { (mg/dl) }\end{array}$ & $150 \pm 57$ & $155 \pm 64$ & 0.68 \\
\hline Total cholesterol (mg/dl) & $198.7 \pm 33$ & $203.7 \pm 40$ & 0.47 \\
\hline $\begin{array}{l}\text { LDL-C } \\
(\mathbf{m g} / \mathbf{d l})\end{array}$ & $98.4 \pm 19$ & $106 \pm 26$ & 0.05 \\
\hline $\begin{array}{l}\text { HDL-C } \\
(\mathbf{m g} / \mathbf{d l})\end{array}$ & $43 \pm 9$ & $45.3 \pm 11.5$ & 0.24 \\
\hline BMI(kg/m $\left.\mathbf{m}^{2}\right)$ & $29.7 \pm 3$ & $29.4 \pm 4$ & 0.71 \\
\hline
\end{tabular}

* Resulted from ANOVA for comparing mean $\pm \mathrm{SD}$ at baseline between groups

No statistically significant differences were found in baseline characteristics between the probiotics, synbiotic or placebo groups (Table 3). The food intakes, physical activity, and anthropometric measures were not different between the probiotics, synbiotic or placebo groups at baseline and remained unchanged during the study (Table 4).

Table 3. Baseline characteristics presented by the three groups (Mean values \pm standard deviations and number with percentages)

\begin{tabular}{|c|c|c|c|c|c|c|}
\hline & & $\begin{array}{l}\text { Total } \\
(n=85)\end{array}$ & $\begin{array}{l}\text { Probiotic } \\
(\mathbf{n}=27)\end{array}$ & $\begin{array}{l}\text { Synbiotic } \\
(\mathrm{n}=\mathbf{3 0})\end{array}$ & $\begin{array}{l}\text { Placebo } \\
(n=28)\end{array}$ & P-value* \\
\hline \multicolumn{2}{|c|}{ Age (years) } & $52.95 \pm 6.3$ & $52.90 \pm 6.3$ & $52.97 \pm 6.8$ & $52.97 \pm 5.9$ & 0.91 \\
\hline \multirow{2}{*}{ Gender } & Male N (\%) & $38(45)$ & $13(48)$ & $13(43)$ & $12(43)$ & \multirow{2}{*}{0.96} \\
\hline & Female N (\%) & $47(55)$ & $14(52)$ & $23(57)$ & $16(57)$ & \\
\hline \multicolumn{2}{|c|}{ Education(years) } & $11.2 \pm 3.6$ & $11.8 \pm 3.8$ & $11.1 \pm 3.8$ & $10.5 \pm 3.3$ & 0.22 \\
\hline \multicolumn{2}{|c|}{ Weight (kg) } & $78.4 \pm 11$ & $77.3 \pm 10.9$ & $77.9 \pm 11.8$ & $79.8 \pm 10.8$ & 0.54 \\
\hline
\end{tabular}

* Resulted from ANOVA for comparing mean \pm SD at baseline between groups 
Table 4. Anthropometric measures, dietary intake and physical activity at the baseline and after 3 and 6 months of intervention in probiotic, symbiotic and placebo groups.

\begin{tabular}{|c|c|c|c|c|c|c|}
\hline & Groups & At baseline & At 3 months & At 6 months & $\begin{array}{l}\text { p-value* } \\
\text { within } \\
\text { group }\end{array}$ & $\begin{array}{l}\text { P-value* } \\
\text { between } \\
\text { groups }\end{array}$ \\
\hline \multirow{4}{*}{ BMI $\left(\mathrm{Kg} / \mathbf{m}^{2}\right)$} & Probiotic $(\mathrm{n}=27)$ & $29.61 \pm 3.5$ & $29.64 \pm 3.7$ & $29.51 \pm 3.6$ & 0.31 & \multirow{4}{*}{0.26} \\
\hline & Synbiotic $(n=30)$ & $29.12 \pm 2.9$ & $29.23 \pm 3.0$ & $29.01 \pm 2.9$ & 0.40 & \\
\hline & Placebo $(n=28)$ & $30.43 \pm 3.2$ & $30.51 \pm 3.3$ & $30.62 \pm 3.4$ & 0.32 & \\
\hline & p-value** & 0.66 & 0.31 & 0.21 & & \\
\hline \multirow{4}{*}{$\begin{array}{l}\text { Total Energy } \\
\text { (Kcal/d) }\end{array}$} & Probiotic $(n=27)$ & $2004.8 \pm 410$ & $2030.6 \pm 422$ & $2004 \pm 379$ & 0.73 & \multirow{4}{*}{0.76} \\
\hline & Synbiotic $(\mathrm{n}=30)$ & $1967.7 \pm 480$ & $2105 \pm 523.5$ & $2094.5 \pm 515$ & 0.52 & \\
\hline & Placebo $(n=28)$ & $2025.6 \pm 384$ & $2013.5 \pm 381$ & $1999 \pm 529$ & 0.55 & \\
\hline & p-value & 0.81 & 0.72 & 0.69 & & \\
\hline \multirow{4}{*}{ Carbohydrate(g/d) } & Probiotic $(n=27)$ & $273.5 \pm 64$ & $270 \pm 55$ & $268 \pm 52.5$ & 0.81 & \multirow{4}{*}{0.67} \\
\hline & Synbiotic $(\mathrm{n}=30)$ & $271 \pm 59$ & $283 \pm 65$ & $286 \pm 60$ & 0.67 & \\
\hline & Placebo $(n=28)$ & $271 \pm 53$ & $273 \pm 53$ & $278 \pm 54$ & 0.83 & \\
\hline & p-value & 0.98 & 0.10 & 0.43 & & \\
\hline \multirow{4}{*}{$\operatorname{Protein}(g / d)$} & Probiotic $(\mathrm{n}=27)$ & $77 \pm 19$ & $76.5 \pm 18$ & $77 \pm 20$ & 0.79 & \multirow{4}{*}{0.80} \\
\hline & Synbiotic $(n=30)$ & $69 \pm 19.7$ & $74 \pm 23$ & $76 \pm 24$ & 0.37 & \\
\hline & Placebo $(n=28)$ & $73 \pm 18.8$ & $76 \pm 19$ & $76 \pm 18$ & 0.32 & \\
\hline & $\mathrm{p}$-value & 0.21 & 0.84 & 0.97 & & \\
\hline \multirow{4}{*}{ Fat $(g / d)$} & Probiotic $(n=27)$ & $67.6 \pm 17$ & $67.3 \pm 15.6$ & $68.8 \pm 15.7$ & 0.45 & \multirow{4}{*}{0.24} \\
\hline & Synbiotic $(\mathrm{n}=30)$ & $68 \pm 14$ & $68.3 \pm 15.6$ & $67.2 \pm 18$ & 0.84 & \\
\hline & Placebo $(n=28)$ & $71 \pm 13$ & $72 \pm 10.6$ & $73.8 \pm 11.4$ & 0.62 & \\
\hline & p-value & 0.54 & 0.42 & 0.24 & & \\
\hline \multirow{4}{*}{ METS } & Probiotic $(n=27)$ & $32.13 \pm 3.5$ & $30.70 \pm 3.0$ & $30.92 \pm 3.0$ & 0.22 & \multirow{4}{*}{0.58} \\
\hline & Synbiotic $(n=30)$ & $32.38 \pm 2.6$ & $31.45 \pm 2.8$ & $31.00 \pm 2.9$ & 0.41 & \\
\hline & Placebo $(n=28)$ & $31.97 \pm 2.7$ & $31.73 \pm 2.8$ & $31.84 \pm 2.4$ & 0.74 & \\
\hline & p-value & 0.82 & 0.37 & 0.41 & & \\
\hline
\end{tabular}

* Resulted from Repeated Measured ANOVA for comparing the changes over time within and between study groups ** Resulted from ANOVA for comparing the changes at each time between study groups

A repeated measures ANOVA with a Greenhouse-Geisser correction determined that total cholesterol, LDL-c, and HDL-c were changed neither within nor between the three groups during the study period. However, mean triglyceride levels decreased significantly in probiotic and synbiotic groups and significantly increased in the placebo group after 6 months of intervention. Post-hoc Bonferroni correction for multiple comparisons revealed that the differences between synbiotic group and placebo group have been statistically significant (Table 5). No serious adverse events were reported by the participants during the study. The only adverse event which has been reported by 12 subjects was mild gastrointestinal complication ( 2 in the probiotic group, 6 in the synbiotic group and 4 in the placebo group, $\mathrm{P}=0.32$ ). 
Table 5. Lipid profiles at the baseline and after 3 and 6 months of intervention in probiotic, symbiotic and placebo group.

\begin{tabular}{|c|c|c|c|c|c|c|c|}
\hline & Groups & At Baseline & At 3 months & $\begin{array}{l}\text { At } 6 \\
\text { months }\end{array}$ & $\begin{array}{l}\text { p-value } \\
\text { time } \\
\text { effect }\end{array}$ & $\begin{array}{l}\text { P-value } \\
\text { between } \\
\text { groups }^{\mathrm{a}}\end{array}$ & $\begin{array}{l}\text { Post- } \\
\text { hoc } \\
\text { group* } \\
*\end{array}$ \\
\hline \multirow{3}{*}{$\begin{array}{l}\text { Triglyceride } \\
(\mathrm{mg} / \mathrm{dl})\end{array}$} & $\begin{array}{l}\text { Probiotic }(\mathrm{n}=2 \\
\text { 7) }\end{array}$ & $157.57 \pm 72.9$ & $148.62 \pm 67.8$ & $140.88 \pm 65.7$ & $<0.001$ & \multirow{3}{*}{$\begin{array}{l}0.02 \\
\mathrm{OP}=0.71 \\
*\end{array}$} & \multirow{3}{*}{ G2/G3 } \\
\hline & $\begin{array}{l}\text { Synbiotic }(\mathrm{n}=3 \\
0)\end{array}$ & $148.05 \pm 52.6$ & $136.74 \pm 44.2$ & $135.79 \pm 43.6$ & $<0.001$ & & \\
\hline & $\operatorname{Placebo}(\mathrm{n}=28)$ & $150.40 \pm 53.2$ & $153.78 \pm 54.9$ & $170.88 \pm 59.7$ & $<0.001$ & & \\
\hline \multirow{3}{*}{$\begin{array}{l}\text { Total } \\
\text { cholesterol } \\
(\mathrm{mg} / \mathrm{dl})\end{array}$} & $\begin{array}{l}\text { Probiotic }(n=2 \\
\text { 7) }\end{array}$ & $207.11 \pm 36.1$ & $197.53 \pm 32.8$ & $196.80 \pm 28.3$ & 0.11 & \multirow{3}{*}{0.36} & \multirow{3}{*}{-} \\
\hline & $\begin{array}{l}\text { Synbiotic(n=3 } \\
0)\end{array}$ & $204.80 \pm 36.3$ & $192.50 \pm 29.7$ & $195.46 \pm 32.0$ & 0.34 & & \\
\hline & $\operatorname{Placebo}(\mathrm{n}=28)$ & $190.86 \pm 29.9$ & $188.31 \pm 30.1$ & $196.82 \pm 36.5$ & 0.32 & & \\
\hline \multirow{3}{*}{$\begin{array}{l}\text { LDL-C } \\
(\mathrm{mg} / \mathrm{dl})\end{array}$} & $\begin{array}{l}\text { Probiotic }(\mathrm{n}=2 \\
\text { 7) }\end{array}$ & $102.20 \pm 24.2$ & $101.31 \pm 7.1$ & $102.98 \pm 19.3$ & 0.78 & \multirow{3}{*}{0.62} & \multirow{3}{*}{-} \\
\hline & $\begin{array}{l}\text { Synbiotic(n=3 } \\
0)\end{array}$ & $104.74 \pm 22.3$ & $100.93 \pm 18.3$ & $99.61 \pm 20.4$ & 0.72 & & \\
\hline & $\operatorname{Placebo}(\mathrm{n}=28)$ & $96.77 \pm 18.2$ & $100.21 \pm 18.7$ & $99.26 \pm 23.1$ & 0.39 & & \\
\hline \multirow{3}{*}{$\begin{array}{l}\text { HDL-C } \\
(\mathrm{mg} / \mathrm{dl})\end{array}$} & $\begin{array}{l}\text { Probiotic }(\mathrm{n}=2 \\
\text { 7) }\end{array}$ & $46.11 \pm 10.8$ & $48.32 \pm 13.4$ & $46.76 \pm 13.3$ & 0.17 & \multirow{3}{*}{0.11} & \multirow{3}{*}{-} \\
\hline & $\begin{array}{l}\text { Synbiotic(n=3 } \\
0)\end{array}$ & $42.41 \pm 9.8$ & $42.18 \pm 7.0$ & $41.83 \pm 9.2$ & 0.66 & & \\
\hline & $\operatorname{Placebo}(\mathrm{n}=28)$ & $43.00 \pm 9.3$ & $44.32 \pm 9.6$ & $41.43 \pm 6.8$ & 0.23 & & \\
\hline
\end{tabular}

${ }^{\text {a }}$ Resulted from Repeated Measured ANOVA for comparing the changes over time between study groups

*OP: Observed Power

**G1= Probiotic group, G2= Synbiotic group, G3= Placebo group

\section{DISCUSSION}

A number of studies have been conducted to investigate the role of probiotics and/or prebiotics in lipid metabolism. Among them, in vitro studies and animal model researches have supported the hypolipidemic effect of probiotics (20). However, human clinical studies have yielded mixed results $(21,22)$.

Up to know, we have not enough documents about the effects of synbiotics on lipid profiles in individuals with prediabetes who are at risk of diabetes mellitus and cardiovascular diseases. The current study demonstrated that consumption of synbiotic supplement in prediabetic individuals for 6 months resulted in a decrease in serum triglyceride levels compared to placebo. Previous animal studies have shown that the gut microbiome may play an important role in serum lipids, supporting the potential of therapies altering the gut microbiome to control triglycerides $(23,24)$. In a previous study by Liong MT et.al (25) the use of a synbiotic food containing Lactobacillus.acidophilus, FOS, inulin, and mannitol has been resulted in decreased serum 
triglycerides, total cholesterol and LDL-C levels and increased concentrations of HDL-cholesterol in hyper-cholesterolemic pigs after 8 weeks. The mechanisms which have been proposed for triglyceride lowering effect by synbiotics may be lipolysis of triglycerides, suppressing the NF- $\kappa \mathrm{B}$ pathway, gut microbiota-SCFA-hormone axis and de-conjugation of intestinal bile salts by bacterial bile salt hydrolase. The influence on TLR4 signaling and pro-inflammatory cytokines might also explain lipid-lowering effects of probiotics and prebiotics(26,27). It is demonstrated that an elevated HDL cholesterol level and decreased in total and LDL-cholesterol are generally regarded as the factors reducing the risk of cardiovascular disease and as the protective factors in diabetes mellitus $(20,28)$. However, our study did not show a significant effect of probiotics or synbiotic on HDL cholesterol levels, total cholesterol and LDL-cholesterol profiles. This result confirms the recent meta-analysis on diabetic patients by Kecheng Yao et al (16) which concluded that the effects of probiotics on cholesterol levels and lipid metabolism are not convincing. Generally, the reports on the association between lipid parameters and probiotic or synbiotic consumption are inconsistent $(29,30)$ which these discrepancies may have been caused by using various probiotic strains, the characteristics of the study population groups, differences in experimental designs, and the length of intervention. It seems that using high-dose multispecies probiotic may be more effective than single-strain. Probiotics in a multi-species compete with each other and create their own mini-ecosystem which forces antagonistic species to strengthen their defense mechanisms (29). Overall, strong clinical trials are still very limited in this field and more studies are needed to determine the true relationship between probiotic or synbiotic supplementation and cardio metabolic risk factors.

\section{Limitation}

Because of long duration of intervention, we had more attrition rate than we had expected in the protocol. So, we used a post-power analysis to cover this limitation.

\section{CONCLUSIONS}

The results of this study showed that 6 months oral supplementation with probiotics and particularly synbiotic decreased the concentration of triglyceride in prediabetic subjects. This finding could warrant future studies to determine the therapeutic and preventive effects of these supplements in individuals at risk of diabetes and cardiovascular diseases. Our findings do not suggest that probiotics or synbiotic are an effective means to favorably affect serum cholesterols. However, it remains possible that other types of prebiotics or strains of probiotics, with different dose patterns, do affect serum cholesterol concentrations. Overall, human interventions of synbiotic and probiotic showed mixed findings on lipid profiles and further works are required.

List of Abbreviations: CVD, cardiovascular disease; T2DM, type 2 diabetes mellitus; LDL, low-density lipoprotein; HDL, high-density lipoprotein; TC, total cholesterol; SCFA, short chain fatty acids; FPG, fasting plasma glucose; BS, blood sugar; OGTT, oral glucose tolerance test; MET, metabolic equivalent of task; SD, standard deviation; ANOVA, analysis of variance. 
Competing Interests: The authors declare no competing interests.

Author Contributions: M.A, A.A, A.F and N.K equally contributed to the conception and design of the research; N.K and M.T.E contributed to the design of the research; N.K and A.F contributed to the acquisition and analysis of the data; M.A and N.K contributed to the interpretation of the data; and M.A, A.F, A.A, M.T.E and N.K drafted the manuscript. All authors critically revised the manuscript, agree to be fully accountable for ensuring the integrity and accuracy of the work, and read and approved the final manuscript.

Acknowledgements and Funding: We would like to thank the study participants for their desirable cooperation. This project was funded by the Isfahan University of Medical Sciences. The funding body played no role in the design, collection, and analysis, interpretation of data, writing of the manuscript or the decision to submit the manuscript for publication.

\section{REFERENCES}

1. Tabrizi R, Moosazadeh M, Lankarani KB, Akbari M, Heydari ST, Kolahdooz F, Asemi $Z$ : The effects of synbiotic supplementation on glucose metabolism and lipid profiles in patients with diabetes: A systematic review and meta-analysis of randomized controlled trials. Probiotics and antimicrobial proteins 2018, 10(2):329-342.

2. Mohamadshahi M, Veissi M, Haidari F, Javid AZ, Mohammadi F, Shirbeigi E: Effects of probiotic yogurt consumption on lipid profile in type 2 diabetic patients: A randomized controlled clinical trial. Journal of research in medical sciences 2014, 19(6):531-516.

3. Pereira DI, Gibson GR: Effects of consumption of probiotics and prebiotics on serum lipid levels in humans. Critical reviews in biochemistry and molecular biology 2002, 37(4):259-81.

4. Hofe CR, Feng L, Zephyr D, Stromberg AJ, Hennig B, Gaetke LM: Fruit and vegetable intake, as reflected by serum carotenoid concentrations, predicts reduced probability of polychlorinated biphenyl-associated risk for type 2 diabetes: National Health and Nutrition Examination Survey 2003-2004. Nutrition research 2014, 34(4):285-93.

5. Shoelson SE, Lee J, Goldfine AB: Inflammation and insulin resistance. The Journal of clinical investigation 2006, 116(7):1793-1801

6. Burcelin R, Serino M, Chabo C, Blasco-Baque V, Amar J: Gut microbiota and diabetes: from pathogenesis to therapeutic perspective. Acta diabetologica 2011, 48(4):257-73.

7. Nicholson JK, Holmes E, Kinross J, Burcelin R, Gibson G, Jia W, Pettersson S: Hostgut microbiota metabolic interactions. Science 2012, 336(6086):1262-7.

8. Yasmin A, Butt MS, Afzaal M, van Baak M, Nadeem MT, Shahid MZ: Prebiotics, gut microbiota and metabolic risks: Unveiling the relationship. Journal of functional foods 2015, 17:189-201. 
9. Wang WH, Chiu YW, Kao SH, Ting WJ, Hsu CY, Cheng HH, Lee HH, et al.: Eight Probiotics Are Effective in Lowering Serum Lipids. Adaptive Medicine 2016, 8(1):1-5.

10. Kumar M, Nagpal R, Kumar R, Hemalatha R, Verma V, Kumar A, Chakraborty C, et al.: Cholesterol-lowering probiotics as potential biotherapeutics for metabolic diseases. Experimental diabetes research 2012, 2012:902917.

11. Tajadadi-Ebrahimi M, Bahmani F, Shakeri H, Hadaegh H, Hijijafari M, Abedi F, Asemi Z: Effects of daily consumption of synbiotic bread on insulin metabolism and serum high-sensitivity $\mathrm{C}$-reactive protein among diabetic patients: a double-blind, randomized, controlled clinical trial. Annals of Nutrition and Metabolism 2014, 65(1):34-41.

12. Upadhyay N, Moudgal V: Probiotics: a review. JCOM 2012, 19(2):76-84.

13. Baroutkoub A, Zamir MR, Beglarian R, Hassan J, Sohrabi Z, Mazloomi SM, Eskandari $\mathrm{MH}$ : Effects of probiotic yoghurt consumption on the serum cholesterol levels in hypercholestromic cases in Shiraz, Southern Iran. Scientific Research and Essays 2010, 5(16):2206-9.

14. Li J, Lei R, Li X, Xiong F, Zhang Q, Zhou Y, Yang S, et al.: The antihyperlipidemic effects of fullerenol nanoparticles via adjusting the gut microbiota in vivo. Particle and fibre toxicology 2018, 15(1):5.

15. Li C, Li X, Han H, Cui H, Peng M, Wang G, Wang Z: Effect of probiotics on metabolic profiles in type 2 diabetes mellitus: A meta-analysis of randomized, controlled trials. Medicine 2016, 95(26):e4088

16. Yao K, Zeng L, He Q, Wang W, Lei J, Zou X: Effect of Probiotics on Glucose and Lipid Metabolism in Type 2 Diabetes Mellitus: A Meta-Analysis of 12 Randomized Controlled Trials. Medical science monitor 2017, 23:3044-3053.

17. Sentell TL, He G, Gregg EW, Schillinger D: Racial/ethnic variation in prevalence estimates for United States prediabetes under alternative 2010 American Diabetes Association criteria: 1988-2008. Ethnicity and Disease 2012, 22(4):451-8.

18. Pandis N, Chung B, Scherrer R, Elbourne D, Altman D: CONSORT 2010 statement: extension for reporting within-person randomised trials. BMJ 2017, 357:1-22.

19. Oguma Y, Osawa Y, Takayama M, Abe Y, Tanaka S, Lee IM, Arai Y: Validation of questionnaire-assessed physical activity in comparison with objective measures using accelerometers and physical performance measures among community-dwelling adults aged $\geq 85$ years in Tokyo, Japan. Journal of Physical Activity and Health 2017, 14(4):245-52.

20. Cho YA, Kim J: Effect of probiotics on blood lipid concentrations: a meta-analysis of randomized controlled trials. Medicine (Baltimore) 201, 94(43):e1714.

21. Lye HS, Rusul G, Liong MT: Removal of cholesterol by lactobacilli via incorporation and conversion to coprostanol. Journal of dairy science 2010, 93(4):1383-92. 
22. Pereira DI, McCartney AL, Gibson GR: An in vitro study of the probiotic potential of a bile-salt-hydrolyzing Lactobacillus fermentum strain, and determination of its cholesterol-lowering properties. Applied and environmental microbiology 2003, 69(8):4743-52.

23. Fu J, Bonder MJ, Cenit MC, Tigchelaar EF, Maatman A, Dekens JA, Brandsma E, et al.: The Gut Microbiome Contributes to a Substantial Proportion of the Variation in Blood Lipids. Circulation research 2015, 117(9):817-24.

24. Allayee H, Hazen SL: Contribution of Gut Bacteria to Lipid Levels: Another Metabolic Role for Microbes? Circulation research 2015, 117(9):750-4

25. Liong MT, Dunshea FR, Shah NP: Effects of a synbiotic containing Lactobacillus acidophilus ATCC 4962 on plasma lipid profiles and morphology of erythrocytes in hypercholesterolaemic pigs on high-and low-fat diets. British Journal of Nutrition 2007, 98(4):736-44.

26. Ouwehand AC, Tiihonen K, Saarinen M, Putaala H, Rautonen N: Influence of a combination of Lactobacillus acidophilus NCFM and lactitol on healthy elderly: intestinal and immune parameters. British Journal of Nutrition 2008, 101(3):367-75.

27. Costabile A, Buttarazzi I, Kolida S, Quercia S, Baldini J, Swann JR, Brigidi P, et al.: An in vivo assessment of the cholesterol-lowering efficacy of Lactobacillus plantarum ECGC 13110402 in normal to mildly hypercholesterolaemic adults. PLoS One 2017, 12(12):e0187964.

28. Kasinska MA, Drzewoski J: Effectiveness of probiotics in type 2 diabetes: a metaanalysis. Pol Arch Med Wewn 2015, 125(11):803-13.

29. Sayin SI, Wahlstrom A, Felin J, Jantti S, Marschall HU, Bamberg K, Angelin B, et al.: Gut microbiota regulates bile acid metabolism by reducing the levels of tauro-betamuricholic acid, a naturally occurring FXR antagonist. Cell metabolism 2013, 17(2):225-35.

30. Xiao JZ, Kondo S, Takahashi N, Miyaji K, Oshida K, Hiramatsu A, Iwatsuki K, et al.: Effects of milk products fermented by Bifidobacterium longum on blood lipids in rats and healthy adult male volunteers. Journal of dairy science 2003, 86(7):2452-61. 